\title{
Tratamento químico de sementes de mamão visando ao controle de Rhizoctonia solani
}

\author{
Sílvia C. Campos ${ }^{1}$, Silvaldo F. Silveira ${ }^{2}$, Roberto F. Silva ${ }^{2}$, Alexandre P. Viana ${ }^{2}$ \& Patrícia M. Conceição ${ }^{1}$ \\ ${ }^{1}$ Departamento de Engenharia Agrícola, Universidade Federal de Viçosa, 36570-000, Viçosa, MG, Brasil; ${ }^{2}$ Centro de Ciências \\ e Tecnologias Agropecuárias, Universidade Estadual do Norte Fluminense, 28013-600, Campos dos Goytacazes, RJ, Brasil
}

Autor para Correspondência: Silvaldo F. Silveira, email: silvaldo@uenf.br

\section{RESUMO}

Avaliou-se a eficiência do tratamento de sementes de mamoeiro com fungicidas no controle de Rhizoctonia solani. Foram realizados

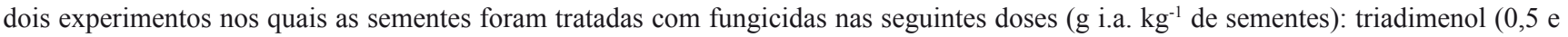
$1,0)$, pencycuron $(1,0$ e 2,0$)$, thiabendazole $(5,0$ e 10,0$)$, fludioxonil $(0,25$ e 0,50$)$, difeconazole $(1,0$ e 2,0$)$, captan $(5,0)$, tolylfluanid $(2,5)$, captan + tolylfluanid $(5,0+2,5)$. Na testemunha, as sementes foram tratadas apenas com água. Em laboratório, avaliou-se o vigor (\%) e a germinação (\%) das sementes. Em casa-de-vegetação, efetuou-se o semeio das sementes tratadas e não-tratadas em substrato infestado com micélio de R..solani AG1-IB. Sementes não tratadas foram plantadas em substrato infestado e não infestado (testemunhas). Não se observaram sintomas de toxidez nas plântulas cujas sementes foram tratadas com os fungicidas testados. Em casa-de-vegetação, a exceção de difeconazole, todos os demais fungicidas reduziram eficientemente a morte de plântulas em pré-emergência e apresentaram elevada emergência de plântulas (\%), igualando-se a testemunha em substrato não infestado, com destaque para a mistura tolylfluanid + captan, que diferiu estatisticamente da testemunha em substrato infestado. Já, quanto ao percentual de plântulas com tombamento em pósemergência, controle satisfatório foi obtido somente quando as sementes foram plantadas em substrato não infestado.

Palavras-chave: Carica papaya, damping off, fungicidas.

\section{ABSTRACT}

Chemical treatment of papaya seeds to control Rhizoctonia solani

The efficiency of fungicides applied on papaya seeds to control Rhizoctonia solani was evaluated in two experiments. Papaya seeds were treated with fungicides (grams of active ingredient $\mathrm{kg}^{-1}$ of seeds): triadimenol $(0,5$ and 1,0), pencycuron (1.0 and 2.0), thiabendazole $(5,0$ and 10,0), fludioxonil $(0,25$ and 0,50$)$, difeconazole (1.0 and 2.0), captan (5.0), tolylfluanid (2.5) and captan + tolylfluanid (5.0 + 2.5 ) and controls (without fungicides). The vigor (seed germination percentage at the first count) and germination (\%) of the seeds were evaluated in laboratory. In greenhouse, seeds were sowed in substrate infested with fungus mycelia, and in the controls, untreated seeds were sowed in infested and uninfested substrate. Seeds without chemical treatment were planted in infested and uninfested substrate as the controls. Toxicity symptoms on the seedlings were not observed for all treatments. Except for difeconazole, all products were efficient in controlling the death of seedlings in pre emergence and increased the emergence of plants in both experiments in greenhouse conditions, but satisfactory post-emergence damping-off control was achieved only by use of uninfested substrate.

Keywords: Carica papaya, damping off, fungicides.

As doenças do mamoeiro (Carica papaya L.) destacam-se economicamente por acarretarem severas perdas durante o cultivo, comercialização e exportação de frutos. No viveiro e em campo, o tombamento ou damping off e a podridão do colo são as doenças de maior importância e Rhizoctonia spp., Pythium spp. e Phytophthora spp. os agentes causais mais freqüentes (Bedendo, 1995).

Dentre as principais práticas recomendadas para o controle do tombamento de plantas, citam-se o uso de sementes sadias, o tratamento químico de sementes e o emprego de práticas culturais adequadas, como o

Parte da Dissertação de Mestrado da primeira autora. Universidade Estadual do Norte Fluminense. Campos dos Goytacazes RJ. 2007. uso de substrato e de tubetes livres de inóculo de fungos fitopatogênicos. Para o tratamento de sementes de mamão, Oliveira e Santos Filho (2000) recomendaram o uso do fungicida captan. Posse (2005) observou que o fungicida benomyl foi eficaz no controle do tombamento das mudas produzidas em substrato infestado com Rhizoctonia solani (Kühn). Este trabalho avaliou a eficiência de diferentes fungicidas no tratamento de sementes de mamão, visando ao controle do tombamento de plântulas causado por $R$. solani.

Os experimentos foram realizados em setembro e dezembro de 2006. As sementes foram obtidas de frutos de mamoeiro 'Golden', colhidos ainda verdes (estádio I de maturação), os quais foram mantidos em repouso em laboratório por sete dias até seu completo amadurecimento. 
Após extraídas, as sementes foram lavadas em água corrente sobre uma peneira e friccionadas com auxílio de uma escova de nylon para a retirada da sarcotesta. Em seguida, foram secas a $37 \pm 1^{\circ} \mathrm{C}$ até atingirem entre 8 e $9 \%$ de teor de água. Após secagem, foram embaladas em envelope de papel aluminizado à vácuo e mantidas a $7 \pm 1^{\circ} \mathrm{C}$ até a instalação do experimento. Os experimentos foram conduzidos em duas épocas, após sete e dez meses da obtenção das sementes. As sementes foram tratadas com cinco produtos formulados em suspensão concentrada (g i.a. $\mathrm{kg}^{-1}$ de sementes): pencycuron $250 \mathrm{~g}$ i.a. $\mathrm{L}^{-1}$ (nas doses 0,25 e 0,5$)$, thiabendazole $485 \mathrm{~g}$ i.a. $\mathrm{L}^{-1}(5,0$ e 10,0$)$, triadimenol 312 g i.a. $\mathrm{L}^{-1}(0,5$ e 1,0$)$, difeconazole 150 g i.a. $\mathrm{L}^{-1}(1,0 \mathrm{e}$ $2,0)$ e fludioxonil $25 \mathrm{~g}$ i.a. $\mathrm{L}^{-1}(0,25 \mathrm{e} 0,50 \mathrm{~g})$; e também com dois produtos em formulação pó molhável (g i.a. $\mathrm{kg}^{-1}$ de sementes): tolylfluanid 500 g i.a. $\mathrm{kg}^{-1}$ de produto $(2,5) \mathrm{e}$ captan $500 \mathrm{~g}$ i.a. $\mathrm{kg}^{-1}$ de produto $(5,0)$, além da mistura captan + tolylfluanid $(5,0+2,5)$. As parcelas testemunha consistiram de sementes não tratadas com fungicida. Os fungicidas foram misturados a $10 \mathrm{~g}$ de sementes acondicionadas em sacos de polietileno, procedendo-se a agitação manual. $\mathrm{O}$ semeio e a instalação dos experimentos foram no mesmo dia em que as sementes foram tratadas.

Avaliou-se a condição sanitária das sementes não tratadas com os fungicidas um mês antes da instalação do experimento I, por meio do teste de Blotter (Neergaard, 1979). Para tanto, as sementes foram acondicionadas sobre uma folha de papel mata-borrão embebida com água esterilizada. Foram analisadas 400 sementes distribuídas em 16 caixas plásticas tipo Gerbox. Procedeu-se à incubação a $30^{\circ} \mathrm{C}$ e fotoperíodo de $8 \mathrm{~h}$ em incubadora tipo BOD, tendo em seu interior uma bandeja com água para manutenção da umidade. Após sete dias de incubação, procedeu-se à análise das sementes sob microscópio esteroscópio e, quando necessário, foram confeccionadas preparações microscópicas das estruturas observadas para auxiliar na identificação dos microorganismos presentes sob microscópio ótico.

O teste de germinação das sementes foi efetuado de acordo com as Regras para Análises de Sementes (Brasil, 1992). Utilizaram-se quatro repetições de 50 sementes dispostas sobre duas folhas de papel germitest e cobertas com uma folha do mesmo papel. O conjunto foi umedecido com água destilada na proporção de 2,5 partes de água por uma parte do peso do papel. Os germinadores do tipo BOD foram regulados para manter a temperatura alternando em torno de $20^{\circ} \mathrm{C}$ por $16 \mathrm{~h}$ de escuro e $30^{\circ} \mathrm{C}$ por $8 \mathrm{~h}$ de luz. Avaliou-se a germinação das sementes aos 14 e 30 dias após a instalação do teste. Para avaliação do vigor, considerou-se a primeira contagem da germinação (\%), realizada após 14 dias de incubação. $\mathrm{O}$ arranjo experimental foi inteiramente casualizado e os dados submetidos à análise de variância. As médias dos tratamentos foram comparadas pelo teste de Tukey a 5\% de probabilidade.

Para avaliar o efeito dos fungicidas no controle do tombamento, nas mesmas duas épocas que se realizaram os testes em laboratório, foram feitos dois ensaios em casa-de-vegetação. Para tanto, sementes tratadas e não tratadas foram semeadas a $1 \mathrm{~cm}$ de profundidade em tubetes de $53 \mathrm{~cm}^{3}$ contendo substrato comercial Substrat ${ }^{\circledR}$ não esterilizado. Para completar o volume de substrato no tubete acima da semente, usou-se o mesmo substrato. Porém, como método de inoculação, as sementes foram cobertas com substrato infestado com micélio de $R$. solani AG1-IB - isolado RH 12 (Silveira et al., 2000). O isolado fúngico foi mantido desidratado em flocos de aveia (Sneh et al., 1986). Para produção do inóculo, o fungo foi repicado para meio de batata-dextrose-ágar (BDA) e incubado por três dias a $25^{\circ} \mathrm{C}$ no escuro. Discos de cultura do fungo em BDA foram transferidos para $50 \mathrm{~mL}$ de meio líquido semisintético (Silveira et al., 2000), em Erlenmeyers de 150 $\mathrm{mL}$ e mantidos a $25^{\circ} \mathrm{C}$, em repouso no escuro. Após quatro dias de incubação, a massa micelial obtida foi prensada em papel de filtro para remoção do excesso de meio e triturada por $1 \mathrm{~min}$ em água mineral ( $10 \mathrm{~g}$ de micélio $\mathrm{L}^{-1}$ de água) em liquidificador, sob alta rotação. A suspensão micelial foi misturada manualmente ao substrato utilizado na cobertura das sementes na proporção de $1,0 \mathrm{~g}$ de micélio fresco. $\mathrm{Kg}^{-}$ ${ }^{1}$ de susbtrato. As bandejas, por sua vez, foram mantidas em casa de vegetação e irrigadas diariamente com água por meio de micro-aspersores.

Foram realizadas as seguintes avaliações: emergência de plantas, obtida pelo percentual de plantas que emergiram, assim consideradas quando o cotilédone em forma de 'joelho' característico rompeu o substrato formando um ângulo de no mínimo $90^{\circ} \mathrm{com}$ a superfície do substrato; índice de velocidade de emergência, obtido pela contagem do número de plantas que emergiram diariamente até o final do experimento e calculado de acordo com a fórmula de Maguire (1962); tombamento em pré-emergência, calculado a partir do percentual de plantas que emergiram em determinado tratamento (NP) pelo número de plantas que emergiram na testemunha (MT), segundo a fórmula [(MT$\mathrm{NP} / \mathrm{MT}]^{*} 100$; plantas tombadas em pós-emergência, aos 45 dias após a semeadura (DAS), contabilizado segundo o número de plantas que apresentaram sintomas de tombamento após a emergência (PD). A percentagem de plantas tombadas (tombamento) em pós-emergência foi calculada pela fórmula $[(\mathrm{MT}-\mathrm{PD}) / \mathrm{MT}]^{*} 100$, sendo $\mathrm{MT}$ o número médio de plantas que emergiram nas parcelas cultivadas em substrato não infestado. Para a determinação da emergência máxima de plantas, do índice de velocidade de emergência e do tombamento em pré-emergência, as avaliações diárias foram conduzidas até que não mais se observou emergência alguma de plantas.

Em casa de vegetação, o experimento foi instalado em delineamento inteiramente casualizado, com duas repetições (uma repetição $=48$ plantas). Os dados foram submetidos à análise de variância e as médias dos tratamentos comparadas pelo teste de Tukey a $5 \%$ de probabilidade. As médias mensais de temperatura e umidade relativa no período experimental foram obtidas em mini-estação climatológica instalada nas proximidades da casa de vegetação. 
Sementes de mamão não tratadas revelaram baixa incidência de microrganismos: Fusarium spp. $(0,5 \%)$, Rhizopus sp. (0,25\%), Aspergillus sp. $(0,25 \%)$ e bactérias $(1,0 \%)$. Este resultado pode ser atribuído ao processo de retirada da sarcotesta, com intensa lavagem das sementes e ao fato delas terem sido armazenadas sob condições de baixa umidade e baixa temperatura. Da mesma forma, Posse (2005) constatou grande redução na contaminação das sementes quando se retirou a sarcotesta, que pode servir como substrato, promovendo o crescimento de microorganismos neste tipo de sementes.

Pencycuron ( 1,0 gi.a. $\mathrm{kg}^{-1}$ sementes $)$, triadimenol $(0,5$ e 1,0$)$, thiabendazole $(5,0$ e 10,0$)$, captan $(5,0)$, tolylfluanid $(2,5)$ e captan + tolylfluanid reduziram a germinação in vitro das sementes de mamão em níveis estatisticamente abaixo da testemunha na primeira condução do experimento (Tabela 1). Pencycuron, triadimenol e a mistura captan + tolylfluanid também proporcionaram menores índices de vigor. Estes resultados foram inesperados desde que não ocorreram quaisquer sintomas de fitotoxidez nas plântulas. Entretanto, no experimento II, a mistura captan + tolylfluanid e o fungicida triadimenol não afetaram o vigor nem a germinação das sementes (Tabela 1). Neste experimento, captan foi o fungicida com o pior índice de vigor das sementes e diferiu significativamente quanto ao vigor das sementes em relação à fludioxonil $(0,25)$ e pencycuron $(2,0)$.

$\mathrm{Na}$ primeira condução deste experimento, os tratamentos com triadimenol apresentaram germinação inferior aos demais fungicidas e a testemunha (Tabela 1). As sementes tratadas com triadimenol $(1,0)$ não germinaram in vitro aos 14 DAS. Todavia, na segunda condução do experimento não houve redução na germinação ou emergência das sementes tratadas com triadimenol ou com qualquer outro fungicida, em relação a testemunha (Tabela 1). Na primeira condução do experimento, a menor percentual de germinação das sementes das sementes não tratadas pode ser atribuído às temperaturas sub-ótimas de incubação. Na segunda condução do experimento, todos os tratamentos, inclusivea testemunhanãotratada, nãodiferiram estatisticamente entre si quanto à germinação in vitro, que foi superior a $85 \%$ (Tabela 1). A redução na germinação in vitro de sementes tratadas com triadimenol no experimento I pode ser também atribuída à má cobertura das sementes por ocasião do tratamento. No segundo experimento, procurou-se corrigir este problema adicionando-se o fungicida mais pausadamente e alternando-se o tratamento com agitação vigorosa das sementes. Pode-se, portanto, inferir que a aplicação de fungicidas em sementes de mamão em formulações líquidas deve ser feita com auxílio de equipamento que permita a melhor distribuição e cobertura possível evitando-se o risco de danos por fitotoxidez. O fato da porcentagem de germinação ter aumentado, quando se utilizaram sementes mantidas por sete até 10 meses após a retirada dos frutos pode ser devido a algum nível de dormência, já que segundo Aroucha (2004) é necessário um período de armazenamento de oito meses para que sementes de mamão da cultivar Golden obtenham mais de $80 \%$ de germinação. Entretanto, estes resultados discordam dos obtidos por Martins et at. (2004) que observaram redução no vigor e na germinação de sementes de mamão após seis meses de armazenamento.

Em casa-de-vegetação, no primeiro experimento, Fludioxonil $(0,25$ e 0,50$)$, pencycuron $(2,0)$, difeconazole $(1,0$ e 2,0$)$, thiabendazole $(5,0$ e 10,0$)$, captan $(5,0)$ e tolylfluanid $(2,5)$ destacaram-se dos demais tratamentos químicos com percentual de germinação superior a $85 \%$, igualando-se estatisticamente a testemunha em substrato não-infestado (Tabela 1).

Nos dois experimentos na casa-de-vegetação, a emergência teve início aos sete DAS, porém, observou-se maior uniformidade na emergência das plantas no experimento II (Tabela 1). A emergência máxima no experimento I foi atingida aos 14 DAS, enquanto que na segunda condução esta se deu aos 10 DAS. As condições de ambiente e as temperaturas mais elevadas registradas no segundo experimento, podem ter favorecido a rápida emergência das plantas, possibilitando o escape ao tombamento em préemergência causado por $R$. solani. Nas proximidades da casa de vegetação, foram registradas as seguintes faixas mensais de temperatura e umidade: de 12,3 a $33,7^{\circ} \mathrm{C}$ e de 26 a $100,0 \%$ $\mathrm{UR}$, durante o primeiro experimento; de 16 a $36^{\circ} \mathrm{C}$ e de 38 a $100,0 \%$ UR durante o segundo experimento.

No primeiro experimento, a testemunha cultivada em substrato não infestado apresentou médias de emergência de plântulas estatisticamente superiores em relação à difeconazole $(1,0)$ e à testemunha em substrato infestado (Tabela 1). Já, pencycuron e triadimenol (nas duas doses), thiabendazole (na dose maior), captan, tolylfluanid e captan + tolylfluanid apresentaram emergência superior a testemunha em substrato infestado, igualando-se à emergência da testemunha em substrato não-infestado. No segundo experimento, a mistura captan + tolylfluanid apresentou média de emergência de plantas $(96 \%)$ maior, porém, estatisticamente superior somente em relação à testemunha em substrato infestado (71\% de emergência).

$\mathrm{Na}$ primeira condução, o maior índice de velocidade de emergência (IVE) foi observado nas parcelas da testemunha cujo substrato não fora infestado e no tratamento com pencycuron $(2,0)$, sendo que estes tratamentos diferiram estatisticamente da testemunha cultivada em substrato infestado e de difeconazole $(1,0)$, tratamentos que apresentaram as menores médias de IVE (Tabela 1). No segundo experimento, não houve diferença significativa entre os tratamentos quanto ao IVE. As maiores médias do índice de velocidade de emergência, neste experimento em relação ao primeiro, permitem inferir maior escape ao ataque do patógeno no solo. Por outro lado, quanto mais lenta a emergência (menor IVE), mais expostas as plântulas ficam aos microrganismos causadores da doença e, conseqüentemente, maior a possibilidade de tombamento. 


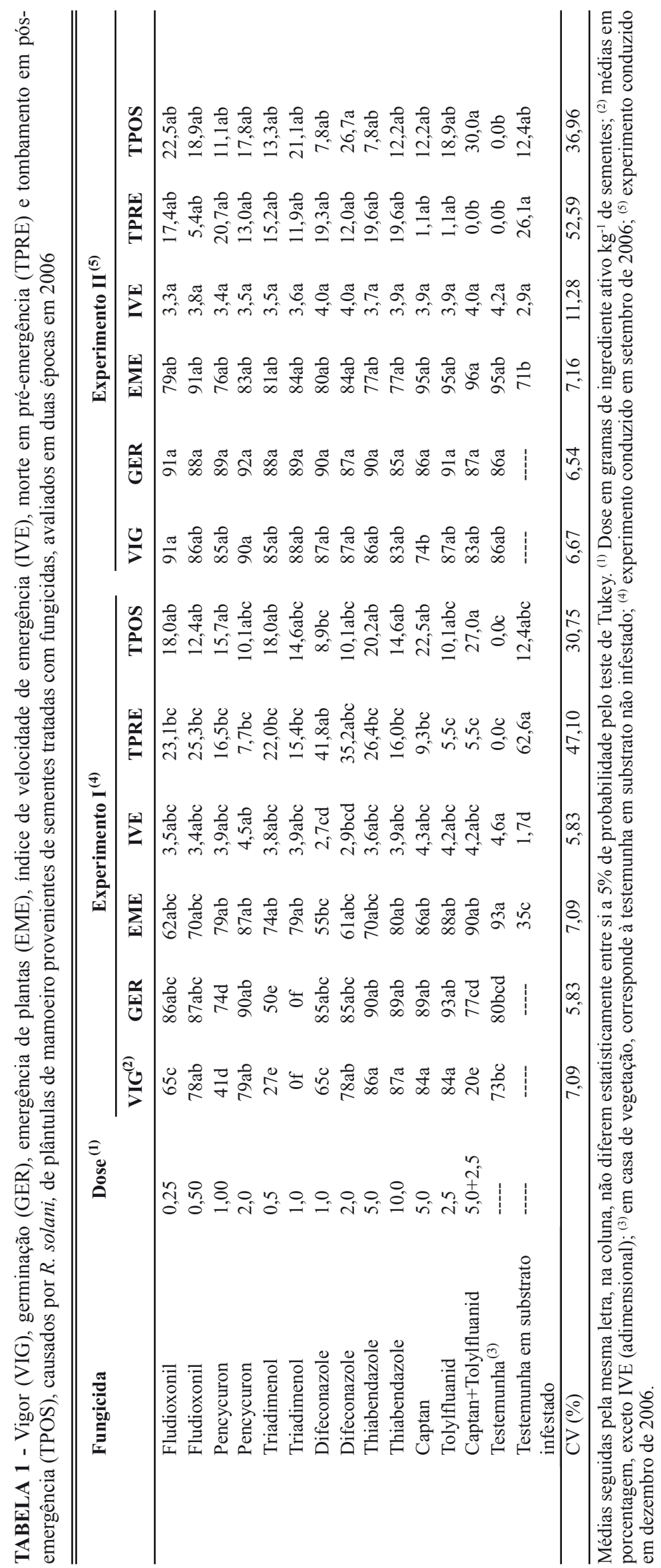


No primeiro experimento, as sementes tratadas com os fungicidas apresentaram maior percentual de emergência e, em conseqüência, menor incidência de morte de plântulas em pré-emergência, com exceção para difeconazole, em ambas as doses, que não diferiu estatisticamente da testemunha em substrato infestado. Na segunda condução do experimento, não se observou apodrecimento de sementes após estas terem sido tratadas com captan + tolylfluanid, igualmente ao observado em substrato não infestado.

Não houve tombamento em pós-emergência ou morte de plantas nas parcelas testemunhas sem tratamento das sementes quando em substrato não infestado, indicando que o uso de substrato limpo ou tratado é importante medida de controle da doença. Por outro lado, os tratamentos que reduziram ou atrasaram a emergência (ex: difenoconazole, experimento I) bem como aqueles que ofereceram maior controle em pré-emergência (ex: mistura de captan + tolylfluanid), apresentaram maiores percentuais de plântulas mortas em pós-emergência. No primeiro caso, o retardo na germinação ocorre em detrimento ao escape à doença. No segundo caso, a disponibilidade de tecido sadio e o adensamento das plântulas favorecem ao tombamento em pós-emergência. Além disso, o isolado do patógeno (RH12，R. solani AG1-IB) utilizado no experimento apresenta crescimento epifítico em partes aéreas de plantas hospedeiras (Silveira et.al., 2000). Isolados epifíticos de $R$. solani são adaptados ao crescimento micelial na superfície do solo, substratos e nas partes aéreas de seus hospedeiros, o que pode resultar no escape do fungo a resíduos de fungicidas presentes na espermosfera. Do mesmo modo se explica a queda na eficiência dos fungicidas usados no tratamento das sementes de mamoeiro, nas avaliações feitas partir dos 45 dias pós-semeio (dados não apresentados). À medida que o tempo passa e os resíduos fungicidas se extinguem no substrato, o crescimento micelial secundário, de uma planta para outra, resulta no aumento da incidência do tombamento de mudas em pós-emergência.

Conclui-se que os fungicidas captan, tolylfluanid, thiabendazole, difeconazole, pencycuron e fludioxonil não são tóxicos às sementes e plântulas de mamoeiro, nas dosagens testadas e quando bem distribuídos nas sementes. $\mathrm{O}$ controle eficiente do tombamento em pré-emergência das plântulas de mamoeiro pode ser obtido a partir do uso de substrato limpo e pelo tratamento de sementes com os fungicidas testados, exceto difenoconazole. A suposta vantagem da utilização de captan em mistura com tolylfluanid em relação a outros fungicidas ou aos mesmos fungicidas aplicados isoladamente, deve-se ao aumento no espectro de ação contra uma extensa gama de fungos, inclusive oomicetos, tais como Phytium e Phytophthora. No viveiro, a remoção de plantas com sintomas de tombamento em pósemergência ou daquelas não emergidas, deve ser empregada para evitar disseminação secundária de patógenos.

A cultura do mamoeiro é geralmente propagada por mudas produzidas em viveiro. Entretanto, não se descarta a possibilidade da semeadura direta no campo, desde que se tenha como acelerar a germinação das sementes e a emergência das plântulas, favorecendo o pegamento e o escape a fitopatógenos e pragas de solo. Para isso, novos experimentos visando o tratamento ou recobrimento das sementes, com fungicidas selecionados neste presente trabalho e outros, deverão ser conduzidos. Todavia, permanece o risco do tombamento em pós-emergência, para o qual o controle químico no campo ainda carece maiores estudos.

\section{AGRADECIMENTOS}

Os autores agradecem ao Conselho de Aperfeiçoamento de Pessoal de Nível Superior - CAPES pelo apoio financeiro na execução deste trabalho.

\section{REFERÊNCIAS BIBLIOGRÁFICAS}

Aroucha EMM (2004) Influência do estádio de maturação, da época de colheita e repouso dos frutos e do osmocondicionamento na qualidade fisiológica de sementes de mamão (Carica papaya L.). Tese de Doutorado. Campos dos Goytacazes RJ. Universidade Estadual do Norte Fluminense.

Bedendo IP (1995) Damping off. In: Bergamin Filho A, Kimati H, Amorim L (Eds.) Manual de Fitopatologia. Vol.1. Princípios e conceitos. São Paulo SP. Agronômica Ceres. pp. 820-828.

Brasil (1992) Ministério da Agricultura e Reforma Agrária. Secretaria Nacional de Defesa Sanitária. Departamento Nacional de Defesa Vegetal. Brasília DF. Coordenação de Laboratório Vegetal. Regras para Análise de Sementes.

Goulart ACP (2002) Efeito do tratamento de sementes de algodão com fungicidas no controle do tombamento de plântulas causado por Rhizoctonia solani. Fitopatologia Brasileira 27:399-402.

Maeda JA, Lago AA, Gerin MAN (1995) Tratamentos com fungicidas no comportamento de sementes de amendoim. Bragantia 54:103-111.

Maguire JD (1962) Seed germination-aid in selection and evaluation for seedling emergence and vigour. Crop Science 2:176-177.

Martins GN, Silva RF, Araújo EF, Vieira HD, Viana AP (2004) Influência do tamanho do fruto, do peso específico e do período de armazenamento na qualidade fisiológica de sementes de mamão cv. Golden. Revista Brasileira de Armazenamento 29:98-103.

Neergaard P (1979) Seed pathology. London. MacMillan Press.

Oliveira AAR \& Santos Filho HP (2000) Doenças. In: Ritzinger CHS, Souza JS (Eds.) Mamão, fitossanidade. Cruz das Almas BA. Embrapa Comunicação para Transferência de Tecnologia. 2000. pp. 37-46.

Pires LL, Bragantini C, Costa JLS (2004) Armazenamento de sementes de feijão com polímeros e tratadas com fungicidas. Pesquisa Agropecuária Brasileira 39:709-715.

Posse, SCP (2005) Produção de mudas do mamoeiro: tratamento 
da semente, substrato e condicionamento mecânico. Tese de Doutorado. Campos dos Goytacazes RJ. Universidade Estadual do Norte Fluminense.

Silveira SF, Alfenas AC, Ferreira FA, Sutton JC (2000) Characterization of Rhizoctonia species associated with foliar necrosis and leaf scorch of clonally-propagated Eucalyptus in Brazil. European Journal of Plant Pathology 106:27-36.

Sneh B, Zeidan M, Ichielevich-Auster M, Barash I, Koltin Y (1986) Increased growth response induced by a nonpathogenioc isolate of Rhizoctonia solani. Canadian Journal of Botany 64:2372-2378.

Recebido 11 Junho 2008 - Aceito 24 Abril 2009 - TPP 7100

Editor Associado: José da Cruz Machado 